\title{
$\mathfrak{I} \mathfrak{n} \mathfrak{a} \mathfrak{a} \mathfrak{l}$
}

\section{Crifte seft.}

ueber bie literarifhen Bewegungen im Panflabiomus. (von Steitt=Norbbeim.) Seite 1

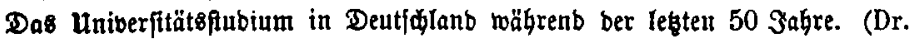

geopolb Reinbarbt.) . . . . . . . . . . . . . . . . -20

Einige Borte zur Rolonifation. (Baron von ber Brilggen.) . . . . . . - 34

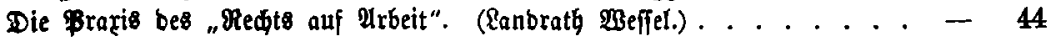



Beriøtigung. (\$. Befeler.) . . . . . . . . . . . . . . . . - 80

Politifde Eorrefponbeng: Die Parteien in 2 ürttemberg. (h.) - Reidstag.

- 2uffibtwang ber nationalfiberalen Bartei. - unfallberflderung. -

Rirdenpolitil. - Dampferlinienfubbention. (w.)....... - 85

Rotizen: Bronfart von Sdyellenborff, Der Dient bes Beneralfabes. -

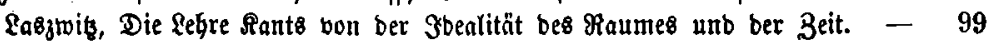

\section{3meite $\mathfrak{b e f t . ~}$}

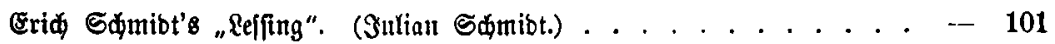

Das Rönigreid Serbien nad̆ feinen mirtbjdaffliden unb Brobuctionsberbältniffen. . . . . . ............ -116

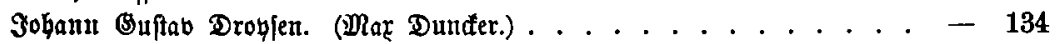

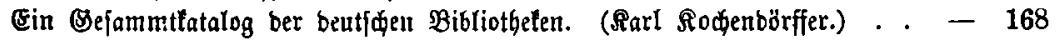

Poltitife Correfponbenz: Die Stuttgarter Stiđłwabl. (h.) - Berlin. (D.) - 175

Rotizen: Dr. b. b. Dften, Die Urbetterberfiderung in Frantreid. - Dr.

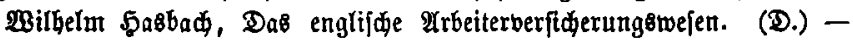
Die $\mathfrak{T u f g a b e}$ ber Rirde unb ibrer inneren Miffton gegentber ben wirth=

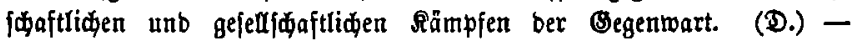



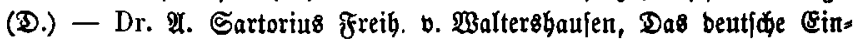

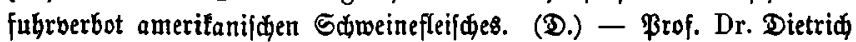

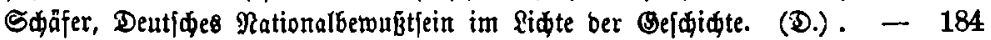

Drittez seft.

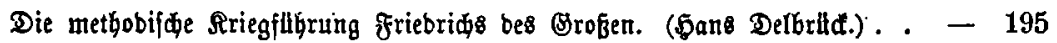

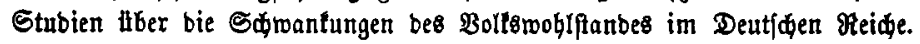

(Dr. E. \$bilippi.) . . . . . . . . . . . . . . . - 213

\$einrid Eaube. (\$uYian Sdmibt.). . . . . . . . . . . . . . -228

Sbatefpeare's Selbftbetenntniffe. (Germanı ஒfaac.)......... - 237

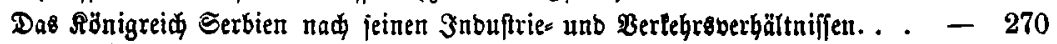




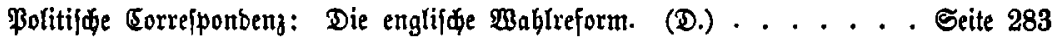

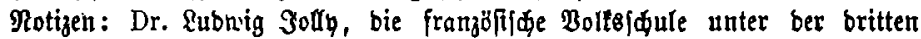

Republit . . . . . . . . . . . . . . . . -288

\section{Bierteళ̧ \$ॄejt.}

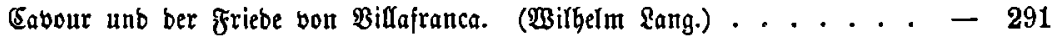

Shatejpeare's Selbftbelenntniffe. (\$̧ermann \$faac.) . . . . . . . - 313

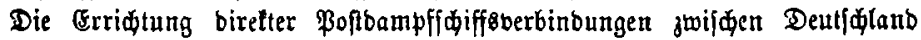

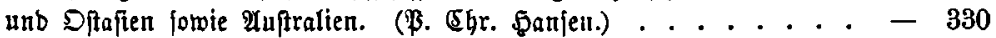

Der (Ehor in ber Tragöbie. (\&ubmig Rieß̄.) . . . . . . . . . . . 339

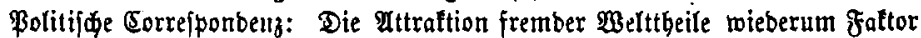
ber europäifden Bolitif. - Die Dreifaiferzufammentunft. - Snnere Bolitil: bie $\mathfrak{B a b l e n}($ w.) ............... 361

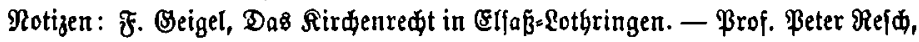
Das Europäifide Bälferredt ber (Segentwart. - Dr. Mbolf Irnbt, $\mathfrak{D a b}$




3uftänbe in Frantreid unt Englanb.............

Flinfte $\mathfrak{E}$ eft.

Die Betämpfung ber Socialbemofratie. (\&. Beterion.). . . . . . . . - 395

Stubien Uber bie Sdimantungen Des Bolfsmohlftanbes in Deutiden Reide.

II. (Dr. E. ß̧illippi.) . . . . . . . . . . . . . . . . . . -418

Das politifde Barteimejen in ben ftanbinabifकen \&änbern . . . . . . 445

Die Entfiebung ber Blumenipiele von Toulouje. (Ebnarb Sdman.) . . . - 457

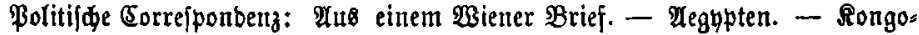

tonferenz. - Die Graunfdweigildge Thronerlebigung. - Die $\mathfrak{B a b l b e m e}$ gung unb ifre Ergebnif. (w.) - Die Reidgtagstwahlen in $\mathfrak{B l i t t t e m b e r g . ~ ( h . ) ~}$

Rotizen. Dr. Ebgar Bauer, Das Rapital unb bie Rapitalmadt. - \&. b. Steill, Die Sanbwirtbjhaft in ber Berwaltung unb bas Brincip ber Redtabbit= bung bes Erunbbefiges. - Sobannes Dverbef, Bompefi in feinen Be=

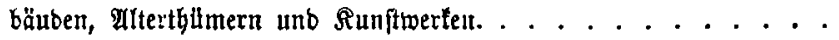

\section{Sediftez Seft.}

Eorneille. (Sulian Sdmibt.) . . . . . . . . . . . . 497

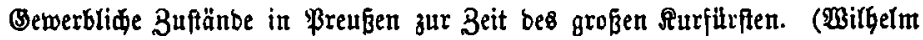
Stieba.) ................... - 506

Eanbrath unb "Pegierung“ in Preupen. (Wans Delbrita.) . . . . . . - 518

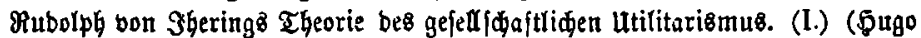
Sommer.) .................. . 533

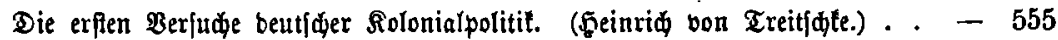

Politifde Eorrefponbenz: 2ustwärtige Politif. - Braunjdmeigifde Frage. Endurtbeil uber bie Mablen. (w.) - Der Meid\&:Etat. (D.). . . . - 567


Tobe Frieberid besิ Broben bis zu ben Freiheitstriegen. - Intile Terrafotten. - Dr. 5. v. Solft, Berfaffungegefdjidte ber Bereinigter:

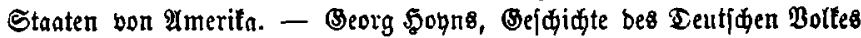
in Staat, Religion, Riteratur uno Runft. - Dstar Sdmebel, Die berren unb \&rafen von Sdiperin. . . . . . . . . . . - S78 